\title{
Research on Construction of Education Fund in Application-Oriented Universities
}

\author{
Bi Tingyan ${ }^{1, \mathrm{a}}$ Zhai Xiaolei ${ }^{2, \mathrm{~b}^{*}}$ Han Jinling $^{3, \mathrm{c}}$ \\ ${ }^{1,3}$ Weifang University, Shandong, China \\ ${ }^{2}$ Ministry of China, Nitional Institute for Curriculum and Textbook Research, Beijing, China \\ abtylook@163.com \\ $b^{*}$ zhaixiaolei_817@163.com \\ cb8877208@163.com
}

\section{Abstract}

Education fund is one of the important sources of funds to run universities. With the rapid increasing of donations from all walks of life especially the alumni to universities, the running conditions of universities have been improved rapidly. Compared with foreign famous universities and domestic "double first-class" universities, the state of alumni donation in application-oriented universities is not so optimistic. Therefore, the application-oriented universities are supposed to learn from the advanced experience of universities at home and abroad in the management and operation of education funds, improve the management system and mechanism of education funds, and promote the modernization of the management system and management capability of universities.

Keywords: universities, education fund, alumni donation

\section{应用型高校教育基金建设研究}

\author{
毕廷延 ${ }^{1,}$ a 翟晓䂞 ${ }^{2,}$ b* 韩金玲 ${ }^{3, c}$
}

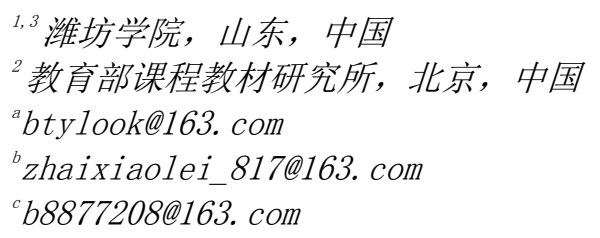

\section{摘要}

教育基金是高校办学经费的重要来源之一。随着社会各界特别是校友对高校捐赠的快速增加，高校的 办学条件得到了快速改善。相比国外名校和国内 “双一流” 高校, 应用型高校的校友捐赠状况不容乐 观。应用型高校要学习国内外高校教育基金管理、运行的先进经验，完善教育基金的管理体制机制， 推动高校治理体系和治理能力现代化。

关键词: 高校, 教育基金, 校友捐赠

\section{1.前言}

根据高等教育学大师潘檚元教授的观点, 以培养应 用型本科人才为主的应用型高校具有以下特点: 以培养 应用型人才为主、以培养本科生为主、以教学为主、以 面向地方为主。相比以培养研究生或从事科学研究为主 的学术型高校, 应用型高校具有独特的发展规律, 不能 效仿学术型高校的发展策略, 其中一个显著的区别就是 学术型高校大都“不差钱”, 而应用型高校大都“捉襟见 肘”。教育基金或教育发展基金, 是高校重要的融资渠 道, 也是高校办学水平、人才培养质量、办学社会声誉 的标志之一。教育基金会是管理教育基金的专门组织机
构, 在高校内可以单设, 也可以与校友会、董事会（理 事会) 等机构合署办公, 即一个部门多块牌子。以哈佛 大学为代表的欧美高校由于办学历史悠久, 校友捐赠、 教育基金建设经验丰富，已经建立了一套比较成熟、运 行高效的教育基金管理机制。国内应用型高校不能完全 照搬学术型高校的做法, 更不能效仿西方高校的做法, 而要根据自身的特点和条件，合理建设本校的教育基金。

国家重视高校通过建立基金会等形式, 通过募捐等 形式筹集办学资金, 改善办学条件。“中国高等教育快 速发展了 40 年，是由政府财政支持做后盾的。高校实 现可持续发展, 需要更大的财力支持, 需要包括校友在 内的来自社会各界的大力捐赠。” ${ }^{[1]} 1993$ 年，国务院颁 布的《中国教育改革发展纲要》中指出: “鼓励和引导 
社会力量捐资、出资办学”; 2011 年, 《国家中长期改革 和发展规划纲要 (2010-2020)》提出: “扩大社会资源进 入教育途径, 多渠道增加教育投入”。社会捐赠中校友 捐赠是主要力量, 但我国高校校友捐资起步较晚, 发展 得也比较慢, 大都呈现出了“总量少, 比例低, 范围窄” 的特点。尤其是应用型高校, 由于受到“马太效应”的影 响, 本身很难吸引校友捐赠, 即使有也比较少, 不同类 型高校之间存在“好的更好, 差的更差”现象。应用型高 校如果较早重视校友捐赠, 采取积极有效措施, 如建立 教育基金会等组织机构, 完善管理运行的体制机制, 校 友捐赠就会收到比较理想的效果, 如杭州师范大学就曾 获得校友马云的巨额捐赠。

\section{2. 研究进展}

高校教育基金建设的核心是组织机构即教育基金 会的建设。国内高校大都将教育基金会与校友会一同写 进大学章程, 这说明高校至少从形式上是重视校友工作 和教育基金会建设的。据不完全统计, 目前“双一流”高 校中已经有超过 130 所建立了教育基金会，而应用型高 校中有不足半数高校建立了教育基金会。1994 年 1 月, 清华大学成为国内建国后第一所建立教育基金会的高 校, 即“清华大学教育基金会”。《清华大学章程》规定, “学校自主接受机构、组织及个人自愿无偿捐赠其有权 处分的合法财产, 捐赠事宜由本校及清华大学教育基金 会有关规章规定。”同年 10 月, 北京工业大学成立教育 基金会, 即“北京工业大学教育基金会”。1995 年, 武汉 大学、天津大学、北京大学等高校建立教育基金会。《北 京大学章程》规定, 学校“接受社会捐赠, 管理捐赠项目 和基金, 支持学校事业发展。”首个分区域建立两个教 育基金会的是中国人民大学，2004 年建立“北京市中国 人民大学教育基金会”, 2017 年建立“深圳市中国人民大 学教育基金会”。2018 年, 天津工业大学和太原理工大 学相继建立教育基金会, 这在国内“双一流”高校中建立 教育基金会是比较晚的了。河南大学起初没有入选“双 一流”高校, 但她是第一家建立教育发展基金会的地方 高校, 成立于 2011 年, 基金会一经建立, 为学校建设 高水平大学获得了 1.2 亿元的捐赠。 2017 年, 河南大学 作为一所河南省与教育部共建的地方高校, 进入 “双一 流”建设高校行列。

对于包括校友捐赠在内的高校筹资问题, 多年来我 们给予了较多的关注。开展了多次实地调研, 查阅了文 献资料, 进行了国内外高校的捐赠对比研究, 应邀参加 了多次高峰学术会议, 取得了一些理论成果。2017 年 7 月 8 日, 《中国高等教育》杂志和北京师范大学高教研 究所在北京举办了 “双一流”与大学筹资学术论坛。这次 论坛很好地贯彻落实了党中央、国务院关于《统筹推进 世界一流大学和一流学科建设总体方案》精神, 论坛以 “双一流”建设与大学筹投资为主题, 以问题为导向, 引 导高校多渠道汇聚资源, 扩大社会合作, 增强“自我造 血”功能, 健全社会支持长效机制。我们在会前向论坛 提交了题为《国内外高校校友捐赠的实践经验与启示》
的论文，被大会接受并安排做大会主题报告。我们认为, 在“双一流”建设背景下，建设一流高校、发展一流学科 需要更多的财力支持, 高校单纯依靠国家专项资金、政 府财政事业定额拨款及所收取的学杂费，不足以支撑 “双一流”建设所需的巨大经费开支，包括校友捐赠在内 的社会筹资，应该引起关注。我们建议，现代社会应该 创造一个校友捐赠机制，完善教育基金会，让校友捐赠 活跃起来，从而更好地丰富发展优质教育资源。应用型 高校要整合各种资源、争取国内外的合作、依靠科研成 果转化所获得收益的支持, 还需要包括校友在内的来自 社会各界的大力捐赠。以美国为代表的国外一流高校, 制定实施的筹资战略及其构建的良好筹资生态系统, 为 我国地方高校制定实施卓越的筹资战略提供了有益的 借鉴和启示。应用型高校建设教育基金会，制定实施卓 越的校友捐赠战略, 需要遵循一定的逻辑: 高校领导要 有校友捐赠的想法-形成校友捐赠的办学理念-制定校友 捐赠的年度计划-做好校友捐赠的战略规划-完善校友捐 赠的相关制度-实施善治的校友捐赠行动-构建良好的校 友捐赠文化生态。我们的这些关于校友捐赠的观点，在 2017 年 7 月 11 日徐州召开的中国高等教育学会院校研 究学术年会论坛上, 再次得到与会专家学者的认同。

\section{3.影响因素分析}

既然应用型高校教育基金主要来源于校友捐赠, 那 就有必要分析一下影响校友捐赠的因素有那些。目前国 内外对校友捐赠的研究集中在以下几个方面: 一是捐赠 行为影响因素研究, 二是捐赠作用研究, 三是捐赠管理 研究。据不完全统计, 国内对校友捐赠研究开始于 1992 年, 直到 2011 开始才逐渐增多起来, 已经有近 400 多 篇相关研究学术论文见刊。

\section{1 捐赠行为影响因素}

根据目前已有的研究, 影响高校校友捐赠行为的因 素可以划分为人口因素 (包括性别、年龄、居住地等)、 社会经济因素（包括就业状况、职业收入、捐赠的税收 减免政策等)、心理因素 (包括自我认知、个人的生活 方式、信念和价值观), 且特别注重校友的在校经历、 学校的教学质量和学校的管理运营情况对捐赠影响的 研究。例如: Belfield, C. Rkbeney, A.P. (2000) 研究 发现校友年龄和个人收入与校友捐赠存在着高度的正 相关关系。James Monks（2003）还认为家庭收入高的 校友捐赠可能性大, 但有家庭, 即已结婚和有孩子的校 友对母校的捐赠较少, 同时, 毕业于语言学、社会科学、 医学、教育专业的校友捐赠较少, 法律专业和自然科学 专业的学生捐赠较多。乐为, 项丹青, 郭金萍 (2009) 研究了影响校友捐赠的相关因素, 发现性别、年龄、校 友志愿与校友赠呈负相关，而在校活动、信任、师生关 系、年收入、学校资助、婚否与校友捐赠呈正相关性。 其中, 信任和在校活动与校友捐赠具有显著的相关性。 
会经济效益的变动, 并用经济学上的投入产出曲线对这 种变动进行了分析 (Jone Stone, 1986; Shisen, 2008)。 也有学者通过对高校和捐赠者博弯支付矩阵的研究总 结出高校社会捐赠的四种行为模式 (谷贤林，2008); 从利益相关者的伦理角度分析捐赠双方应具备的伦理 关系, 提出了科学评价捐赠行为的伦理向度 (莫蕾钰, 洪成文，2015)。

\section{4.对策与建议}

国内高校教育基金会建立 26 年来，不少高校通过 教育基金会接受了大量的社会捐赠，尤其是校友捐赠。 高校教育基金会的发展呈现积极健康态势，管理运行模 式在不断探索中趋于成熟，“为推进高校教育基金会的 发展,要从健全法制政策环境、加大宣传力度、规范信息 披露、重视审核监管、建设专业投资团队等方面加强高 校教育基金管理"[2]。

\section{1 完善教育基金治理体制}

结构决定功能。建设应用型高校教育基金，成立相 应的专门管理机构是必要的，如应用型高校教育基金会、 教育发展基金会等。成立的教育基金会，应该明确在学 校管理体制中的功能和作用，明确教育基金会的内设机 构和组成人员，明确机构内工作人员的职责和权利，应 该有相应的工作经费保障。目前超过半数应用型高校还 没有建立教育基金会，这与新时代的教育发展格局不相 符合。高校吸引高层次人才、完善办学条件, 没有充足 的办学经费是不行的。成立教育基金会的一个重要目的, 就是通过以校友捐赠为主渠道的方式为学校建设和发 展提供尽可能多的办学经费。应用型高校要建立健全运 行高效的筹资管理体制, 密切关注校友生态并挖掘社会 资源, 创新并激发校友捐赠的内生动力系统, 要健全公 开透明的校友捐赠运营机制。规范高效的教育基金管理, 需要有专业化高效的管理团队, 让专业的人来管理专业 的事, 才能确保管理的效果。

\section{2 健全教育基金运行机制}

成立应用型高校教育基金会是建设教育基金的第 一步。但是存在一个现实问题是“快速发展过程中高校 教育基金会还存在治理结构不清、制度建设不完善等问 题”[3]。有没有科学合理的基金会运行机制，是检验基金 会效能的重要标志。经常有校友问及如何向学校捐赠的 问题, 他们问的最多的是将资金或财物捐给学校的哪个 部门以及捐赠之后如何保障其发挥作用的问题。如果学 校没有教育基金会，人家也找不到捐赠管理规章制度， 更不能预期捐赠的后果，因此他们只好作罢，失去了捐 赠的动力。应用型高校教育基金建设，关键是要建立健 全教育基金会的系列规章制度，把教育基金管理的权力 关进制度的笼子里，才能发挥其应有的作用，而不会因
郭建，2009); 经济学角度认为捐赠是经济学研究的新 领域, 指出捐赠是经济资源的再分配过程, 必将引起社 
强职能部门工作人员的业务能力建设。

为人员的变更、领导的更替的问题出现纰漏。应用型高 校教育基金的制度建设，包括教育基金会章程建设及包 括人才队伍在内的系列基金会管理制度等。

\section{3 建设浓厚的校友文化氛围}

榜样的力量是无穷的。研究表明, “大学捐赠基金 的发展与培养学生的质量有着显著的正向关系。”[4]应用 型高校建设教育基金的另一个重要目的, 是发挥其育人 功能。一直以来研究校友捐赠关注的重点是断裂的来看 校友行为本身，但校友与高校之间的关系才是校友捐赠 的动因。任何人的行为都离不开与他人的互动。立足社 会网络的理论基础, 能够发现校友与高校之间存在着连 带强度和信任关系。吸引有成就的校友为母校捐赠, 哪 怕是“一元钱”捐赠, 也能丰富发展教育基金。“情感维 护是高校校友捐赠长效发展的广泛基础。重视头部市场、 忽视尾部市场是我国高校校友捐赠的主要问题。” ${ }^{[[]}$在新 冠肺炎疫情期间, 不少高校校友向母校捐赠防疫物资和 钱款, 充分体现了校友关爱社会、回报母校、奉献爱心 的社会责任感, 为在校生树立了光辉的榜样。当在校生 享受到校友捐赠带来的获得感时, 他们对校友的亲切感、 接近感、敬慕感油然而生, 这种感觉会变成鞭策他们学 习进步的内生动力, 激励他们增强创新意识和创新精神, 从而促进他们尽快健康成长成才。

\section{4 教育基金的绩效评价}

绩效评价在教育基金建中设的作用不能忽视。应用 型高校教育基金的建设, 要重视对基金管理的绩效评价, 包括筹集资金的能力评价和管理运行的效能评价。教育 基金筹集不仅是职能部门几个人的责任, 也是学校办学 知名度、美誉度的体现, 因此是全校教职员工共同的责 任。由于不同应用型高校的筹资能力存在较大的差距, 同类高校教育基金建设的状况大相径庭。事实上, “团 队成员胜任能力、项目设置科学性和总结反馈机制对于 提升基金会服务质量有重要作用。”[6]管理运行的效能主 要体现在学校职能部门的工作规范和效率, 是指把筹集 的资金和财物不仅要管理的好还要运用的好, 因此要加
强职能部门工作人员的业务能力建设。

\section{项目基金}

本文系中国高等教育学会高等教育科学研究“十三 五”, 规划课题 2017 年高校校友工作专项重点课题《地方 高校校友捐赠机制及评价研究》 (2017XYZD03); 潍坊 学院 2018 年高等教育研究立项课题《应用型高校教育 基金建设研究——基于校友捐赠的机制与评价》 (2018GZ005)的阶段性成果之一。

\section{REFERENCES}

[1] Bi T.Y, Zhai X.l, Qu Zh. G. A study on the financing of local colleges and universities [C]. Singapore Management and Sports Science Institute (Singapore), Information Engineering Research Institute (USA) .Proceedings of 2018 3rd ISSGBM International Conference on Social Sciences and Education (ISSGBM-SSE 2018).Singapore Management and Sports Science Institute (Singapore), Information Engineering Research Institute (USA): Intelligent information technology application society,2018:454-460.

[2]Cao CH.Y, Zhai Y.F.Management problems and solutions of University Education Foundation[J]. Science and technology in Chinese Universities,2018(08):70-71.

[3]Chen T.R. On the internal control of University Education Foundation[J]. Accountant,2019(11):55-57.

[4]Zhang H,Wan H.Y, Hong C.W. An empirical study on the development and influencing factors of University Endowment Fund in China[J]. Research on Educational Accounting,2016(01):83-84.

[5]Gao Y. Emotional maintenance: a broad basis for the long-term development of alumni donation in Colleges and Universities -- Based on the long tail theory[J]. Friends of accounting, 2016(07):112-115.

[6]Sun Zh.Q, Yu H.B, Huang J.P. Research on service quality management of University Education Foundation Project Based on QFD and Kano[J]. Educational Observation,2019,8(19):7-11. 